\title{
Wait or Buy? The Strategic Consumer: Pricing and Profit Implications
}

\author{
CK Anderson and JG Wilson \\ Richard Ivey School of Business, Ontario, Canada
}

\begin{abstract}
Using tools from operations research, airlines have, for many years, taken a strategic approach to pricing the seats available on a particular flight based on demand forecasts and information. The result of this approach is that the same seat on the same flight is often offered at different fares at different times. Setting of these prices using yield-management approaches is a major activity for many airlines and is well studied in the literature. However, consumers are becoming increasingly aware of the existence of pricing strategies used by airlines. In addition, the availability of airline travel pricing on the Internet affords consumers the opportunity to behave more strategically when making purchase decisions. The onset of the information age makes it possible for an informed consumer or a third party, such as a travel agent, to obtain demand information similar to that used by the airlines. In particular, it is possible for consumers or travel agents to purchase historical data or to obtain it by monitoring the seats that are available at various prices for a given flight. If a consumer understands the pricing strategy and has access to demand information, he/she may decide to defer purchase of a ticket because they believe that a cheaper seat may yet become available. If consumers were to make use of this information to make such strategic purchasing decisions, what would be the impact on airline revenues? The purpose of this paper is to investigate these impacts. This work indicates that use of standard yield management approaches to pricing by airlines can result in significantly reduced revenues when buyers are using an informed and strategic approach to purchasing. Therefore, when airlines are setting or presenting prices, they should investigate the effect of strategic purchasing on their decisions.
\end{abstract}

\section{Introduction}

Airlines have been among the first to exploit the opportunities presented by the digital economy. Each year an ever-increasing fraction of their tickets are sold over the Internet. Revenues from Internet bookings totaled $\$ 276$ million in 1996 , tripled to $\$ 827$ in 1997 , topped $\$ 3.3$ billion in 
1999. ${ }^{1}$ Recent surveys have online airline tickets sales at $\$ 16$ billion in $2001-$ forecast to reach $\$ 40$ billion by $2007 .^{2}$ Airline information systems instantaneously record ticket sales and correspondingly reduce the number of available seats on a given flight. Instantaneous availability of purchase data is one of the major competitive advantages of the new economy.

Airlines have been very successful at using dynamic pricing and revenue management to increase their profitability. Revenue management is the "practice of controlling the availability and/or pricing of travel seats across different booking classes with the goal of maximizing expected revenues or profit'. ${ }^{3}$ In the airline industry, revenue management focuses on selling the right seat to the right customer at the right time for the right price. The result is that fares on a flight can differ dramatically. Segmentation of customers is achieved, for instance, by restrictions on refunds, requiring a Saturday night stay or advance purchase. Even a small percentage increase in revenue per flight can have important effects on an airline's profitability. In fact, American Airlines attributes over $\$ 500$ million in additional annual revenues to its revenue management activities. ${ }^{4}$ The impact of revenue management is enforced by a McKinsey \& Co. study analyzing Compustat data for 1000 companies, indicating that price has the most dramatic impact on profits (versus costs or volumes) as a $1 \%$ increase in price (revenues) generates a $7.4 \%$ increase in profits. ${ }^{5}$ Revenue management is one of the great success stories of Operations Research techniques applied to current management issues.

It is not unusual for an airline to open a flight for bookings up to a year in advance. The selective availability off are classes and the management of that availability are what constitute revenue management. Figure 1 indicates a typical price profile of the lowest available fare from opening to departure. Fares start at a moderately high level (segmented towards those risk-averse travelers who book extremely early), decrease in time (targeted towards the selective leisure segment) and finally dramatically increase for sale to less price sensitive business clients, sometimes with the possibility of last minute discounted (standby) fares.

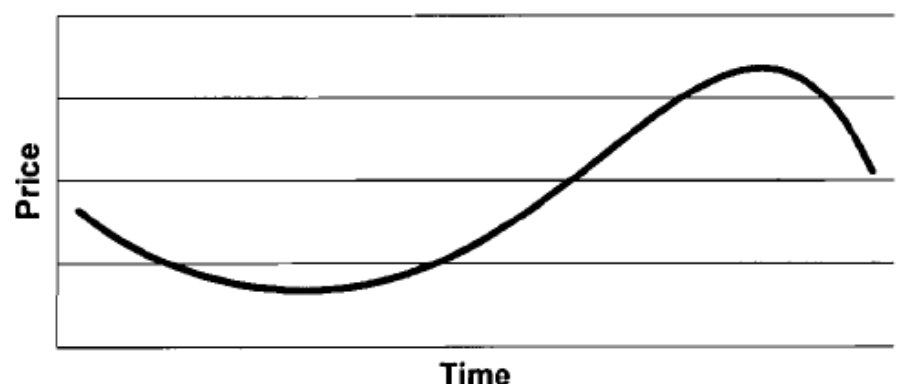

Figure 1 Typical price profile. 
Revenue management is not limited to the airlines. Its principles are suitable for numerous retail and service industries, including advertising, entertainment, car rental, cruise ships and flexible manufacturing facilities. ${ }^{6}$ Coulter $^{7}$ presents extensions of revenue management into managing retail inventories for holiday shopping.

Generally speaking, revenue management is suitable for any business which has some degree of fixed capacity, an ability to segment customers for a perishable product and/or service with relatively low variable costs and fluctuating, but monitored, demand. ${ }^{8}$ Subrahmanyan ${ }^{9}$ discusses how these principles can be applied to pricing in general, indicating how quantitative approaches such as revenue management can be used in retail pricing decisions. The pricing profile of Figure 1 is common to situations of price buildup (typical of situations where demand increases with time, or less price sensitive customers purchase later versus sooner), but the principles may also be applied to situations of price drawdown (such as fashion retailing), where the retailer's decision is when to discount (and by how much) versus curb discounting.

There are a number of papers that look at intertemporal price discrimination. Stokey ${ }^{10}$ and Landsberger and Meilijson ${ }^{11}$ assume that consumers differ in their reservation prices for a commodity and consider the effect this can have on monopolistic pricing. Besanko and Winston ${ }^{12}$ provide a gametheoretic analysis where consumer reservation prices are distributed uniformly on an interval and a monopolist must set a price in each of a number of periods. Lazear ${ }^{13}$ looked at strategic buyer behavior in retail settings, concluding that customers may wait for lower prices unless they perceive there is a large demand for the item, potentially losing out to other customers. Elmaghraby et $\mathrm{al}^{14}$ examine the potential impact of the Internet on pricing policies and indicate the advantage of a more active price markdown mechanism. They indicate that while most research assumes a customer will make a purchase immediately if the price is below the customer's perceived value of the good or service, in fact he might wait for the next price markdown instead of purchasing at the current price. Gallego and van Ryzin ${ }^{15}$ consider optimal dynamic pricing of goods when demand is a price sensitive stochastic point process but consumers do not act strategically.

We focus on the airline industry in an effort to illustrate opportunity for strategic consumer purchase behavior and highlight the benefits to the consumer by indicating the possible losses to the airline. The conclusions we draw, while focused on airlines, are extendable to other business areas as more information becomes available via the Internet or other sources and consumers or agents become more knowledgeable. 
We start with a brief description and illustration of the most commonly used revenue management approach. We then show how to calculate the probability that a closed fare class may reopen in the future. This probability is the key to strategic behavior on the part of the customer. If it is sufficiently high, the customer will delay purchasing a ticket in the hope that a cheaper fare will become available. The impact on airline revenues of such strategic behavior is investigated via extensive simulations for various scenarios and levels of risk aversion.

\section{Strategic Pricing Decisions}

The marketplace typically dictates fare offerings in the airline industry. Airlines seek to maximize revenue by allocating plane capacity to the various fare classes. Littlewood ${ }^{16}$ considered the case of two fares-full and discounted. The approach is to reserve capacity (seats) for the full fare class (ie set a 'protection level' for the full fare class) equal to the (1-r/R) fractile of the demand distribution for full fares, where $r$ represents the revenue from a discount fare and $R$ the revenue from a full fare. This approach is similar in many ways to that of the standard 'Newsperson problem' from the operations research literature. One intuitive rationale behind this is as follows: seats should be added to those reserved for full fare customers until the expected marginal seat revenue from such an allocation no longer exceeds the revenue from a discount customer. So choose the protection level for full fares to be the largest integer $\mathrm{n}$ that satisfies

$$
R P[D \geqslant n]>r,
$$

where $D$ is the demand for full fare seats.

Note that one issue for the airlines in determining the demand (D) distributions is that recording of demand data usually stops when a booking limit is reached. As new ways of recording information become available through such channels as the Internet, this should become less of an issue. However, to date, it poses interesting statistical challenges.

Belobaba ${ }^{17}$ extended this approach to multiple fare classes. The approach is as follows: work out a protection level for the highest fare class from the second highest class as above; then amalgamate the two highest fare class into one class, setting a protection level (as above) between the amalgamated class and the next highest; continue sequentially with this approach until one has obtained (nested) protection levels for all fare classes above the least expensive. This approach is illustrated below with a three-fare example. 


\section{Example 1: Calculating Static Protection Levels}

Suppose there are three fares (full, saver and supersaver) with revenues of $\$ 300, \$ 200$ and $\$ 100$, respectively. Assume historic demand for full fares is normally distributed with a mean of 15 and a standard deviation of 5 while saver fares are normal with a mean of 25 and a standard deviation of 10. Then the protection level for full fares is the (1-200/300) fractile of the demand distribution for full fares, that is, 12.85 . In order to calculate the protection level for the saver fare class, amalgamate full and saver into one class. The demand distribution for this amalgamated class is a normal random variable with a mean of $15+25$ and a variance of $25+100$. The average fare in this amalgamated class is the demand weighted average of the $\$ 300$ and $\$ 200$ fare classes, that is,

$$
(300 \times 15+200 \times 25) /(15+25)=238
$$

So the protection level for this amalgamated class is the (1-100/238) fractile of a normal distribution with a mean of 40 and variance 125 , that is, 42.23 . So 12 seats would be reserved for full fares and 42 seats should be reserved for full and saver fares combined.

The above method of allocating seats to fare classes is static. However, Belobaba also suggests applying this in a dynamic fashion. For a given number of periods before departure of a flight, an airline will have demand information for each fare class. When the flight opens for booking, a set of protection levels is obtained using historical demand distributions from that point to departure. One period later, the airline recomputes the protection levels taking into account how many seats have been sold and the demand patterns from this new point onwards. This is called the 'expected marginal seat revenue' or EMSR approach.

A periodic-review approach is generally adopted. 'No revenue management system attempts full assessment of each booking request in real time'. Airlines continuously collect data on customer reservations. Given the volumes of data, they aggregate this data into similar periods, typically 16 or 18 periods. The periods are longer when the flight first opens for bookings and decrease (to less than a day) as the flight approaches departure. This aggregated data can then be used in a more dynamic fashion to improve seat allocations.

Considerable effort has been placed upon deriving and testing both Littlewood's rule and its extensions. Bhatia and Parekh ${ }^{18}$ and Richter ${ }^{19}$ provide derivations for Littlewood's model. Titze and Greisshaber ${ }^{20}$ provided simulation results, testing Littlewood's model by simulating realistic passenger behaviors for a four-period model. Similar simulation results can be found in Mayer, ${ }^{21}$ where he 
indicated that larger losses and expected revenue results as the ratio of low-to-high fare decreases and when controls deny too many low-fare customers. Pfeifer ${ }^{22}$ extends the model to consider the possibility that the next customer may purchase a full fare ticket if a discount seat is unavailable. Leg-based approaches to seat allocation (like EMSR), which ignore the impacts of revenue from connecting passengers, continue to form the basis of most revenue management systems today. ${ }^{23}$

\section{Example 2: Extending to Dynamic Protection Levels}

We will now consider an extension to the static approach illustrated in Example 1. This example is based on the same basic assumptions as the previous example. Suppose there are three periods before the flight departs, and the airline models the demand for each period as a normal random variable with means and standard deviations as shown in Tables 1 and 2. Applying the dynamic version of EMSR, protection levels are set at the beginning of each period. These are shown in Table 3.

At the beginning of period 1 (three periods before the flight departs) 12 seats are set aside for full fare and 42 are set aside for full and saver fares combined. Thus, for a 50 - seat plane, eight seats may be sold at the supersaver fare. Often airlines will allow some level of overselling to compensate for the fact that not all customers with tickets show up at departure. For example, in the presence of overbooking, the airline may take 55 reservations for the 50 seat plane-under these circumstances up to 13 seats may be allowed for sale to the supersaver fare. At the beginning of period 2 (two periods before the flight departs) new protection levels are calculated. If there are enough seats left, 12 are now reserved for full fare and 29 are reserved for full and discount fares. Suppose, for instance, this is a 50seat plane and 25 seats were sold during the first period, then 12 of the remaining seats will be reserved for full fare customers and the remaining seats for saver customers. Since there are only 25 seats left and the protection level for full and saver combined is 29 , no supersaver fares will be offered during this period.

The previous examples illustrate the main approach used by airlines for strategic pricing. As consumers become more aware of the pricing strategies for airline seats, they can also become more strategic in their purchasing behavior. 
Table 1 Demand distribution for full fares by period number

\begin{tabular}{lccc}
\hline & \multicolumn{3}{c}{ Period no. } \\
\cline { 2 - 4 } & 1 & 2 & 3 \\
\hline Mean & 0.5 & 4.5 & 10 \\
Standard Deviation & 0.5 & 2.8 & 4.12 \\
\hline
\end{tabular}

Table 2 Demand distribution for saver fares by period number

\begin{tabular}{lccc}
\hline & \multicolumn{3}{c}{ Period no. } \\
\cline { 2 - 4 } & 1 & 2 & 3 \\
\hline Mean & 12 & 10 & 3 \\
Standard deviation & 8 & 5.85 & 1.5 \\
\hline
\end{tabular}

Table 3 Protection levels for fares with demand distributions as given in Tables 1 and 2

\begin{tabular}{lccr}
\hline Protection level & \multicolumn{3}{c}{ Period no. } \\
\cline { 2 - 4 } & 1 & 2 & 3 \\
\hline Full & 12.85 & 12.35 & 8.23 \\
Full and saver & 42.23 & 29.57 & 14.56 \\
\hline
\end{tabular}

\section{Strategic Consumer Behavior}

Consumer knowledge of the seat allocation process, combined with the reduction in cost/time of determining fare offerings, has created new opportunities for airline consumers. If the consumer has awareness of the price-time curve for an airline seat, as shown in Figure 1, and has the ability to determine where current fare options are located along this curve then the consumer might engage in strategic purchasing behavior.

An individual customer interested in buying only one ticket will not go through the calculations for finding the probability that a fare class will reopen. However, the ubiquitous nature and comprehensiveness of the material on the Internet can make such calculations no more difficult than accessing a website and entering basic information. A basic theme of this paper is that airlines and other users of revenue management techniques must be ready for the impact this can have on their revenues.

\section{The Probability that a Fare Class Will Reopen}

The key to strategic consumer behavior is the consumer's belief that a cheaper fare class will open if it is not currently available. In this section, we illustrate how to calculate the probability that a fare class will reopen, given that it is now closed. In order to keep the notation to a minimum we again 
assume, without loss of generality, that there are only three fares (full, saver and supersaver) and will demonstrate how to calculate the probability that supersavers will become available at some period in the future if this class of fare has just been closed.

Let $F_{i}$ and $S_{i}$ denote the random variables for demand during period $i$ for full and saver fares, respectively. Let $f_{i}$ and $s_{i}$ denote the protection levels for full fares and the combination of full fares and saver fares, respectively, during period $i$.

Suppose a customer, just prior to the beginning of period k, discovers that there are no supersavers available and that the current capacity (ie number of seats on the airplane minus number of seats already sold) is C. One probability of interest to the customer is the probability that supersavers will once again be available at the beginning of period $k+1$. The number of saver fares that will be requested during period $k$ is given by the random variable $S_{k}$. However, this does not necessarily represent the number of saver fares that will be sold. No more than $C-f_{k}$ saver fares may be sold since $C$ is the remaining plane capacity and $f_{k}$ seats are reserved for full fares. No saver fares may be sold if the current capacity of the plane is less than the reserve level, $f_{k}$, for full fares. Thus, the number of saver fares that will be sold during period $k$ is given by

$$
\min \left\{S_{k},\left(C-f_{k}\right)^{+}\right\}
$$

where the notation a+ is defined as follows:

$$
a^{+}=\max (a, 0)
$$

Thus, the capacity of the plane at the end of period $k$ is provided by the random variable

$$
C_{k}=\left[C-F_{k}-\min \left\{S_{k},\left(C-f_{k}\right)^{+}\right\}\right]^{+}
$$

Fares in the supersaver class will only open up at the beginning of period $k+1$ if this capacity exceeds the protection level, $s_{k+1}$, for the saver and full fare classes combined for period $k+1$. So, if a customer finds that the supersaver class is closed at the beginning of period $k$ and the current capacity of the plane is $C$, then the probability a supersaver fare will be available at the beginning of period $k+1$ is simply

$$
P\left[C_{k}>s_{k+1}\right]
$$

This probability is straightforward to calculate since the distributions of $F_{k}$ and $S_{k}$ are known. 
If supersavers do not reopen for sale in period $k+1$, the possibility exists that they may still reopen sometime in the future. Under the assumption that supersavers do not reopen, the capacity of the plane at the end of period $k+1$ (ie the beginning of period $k+2$ ) is as follows:

$$
C_{k+1}=\left[C_{k}-F_{k+1}-\min \left\{S_{k+1},\left(C_{k}-f_{k+1}\right)^{+}\right\}\right]^{+}
$$

In general, for $i>k$, the capacity at the end of period $i$ is given by the recursive expression

$$
C_{i}=\left[C_{i-1}-F_{i}-\min \left\{S_{i},\left(C_{i-1}-f_{i}\right)^{+}\right\}\right]^{+}
$$

Thus, the probability that a supersaver will open at some stage in the future is

$$
\begin{aligned}
& P\left[C_{k}>s_{k+1}\right]+P\left[C_{k} \leqslant s_{k+1}, C_{k+1}>s_{k+2}\right] \\
& \quad+P\left[C_{k} \leqslant s_{k+1}, C_{k+1} \leqslant s_{k+2}, C_{k+2}>s_{r+3}\right]+\cdots
\end{aligned}
$$

The first probability in the above expression is the probability that a supersaver opens up at the beginning of period $k+1$. The second probability is the probability a supersaver does not open at the beginning of period $k+1$ but opens at the beginning of period $k+2$. The third probability above is the probability that the supersaver is not available at the beginning of periods $k+1$ or $k+2$ but is available at the beginning of period $k+3$, etc.

The above expressions are reasonably straightforward to calculate numerically. This is because the underlying random variables, $F_{i}$ and $S_{i}$, have known distributions.

\section{Pricing and Profit Implications of Strategic Buyers to Airlines}

We will investigate, via extensive simulations, the impact on revenues of strategic consumer behavior. In these simulations, we consider a 50-seat plane with three possible fares (full, saver and supersaver). Specifically, we investigate a 'saver' customer, that is, a customer who will purchase a saver fare unless a supersaver fare is currently available or the probability of a supersaver fare becoming available is sufficiently high, in which case a purchase decision will be postponed.

Variables that can influence revenue include the demand factor, the number of fare reallocation periods and the price differential between fare classes. The demand factor is defined to be expected demand for seats on the flight divided by the aircraft capacity. The number of fare reallocation periods is the number of times that the airline will recalculate protection levels.

Assume that protection levels are set according to the EMSR model. For the simulations, the means and standard deviations of total demand for each fare class are as shown in Table 4. The table 
indicates that $35 \%$ of demand was from full fare consumers, with $30 \%$ from saver fares and $35 \%$ from supersavers. The demand was split into three periods, with $30 \%$ occurring in the first period, $40 \%$ the second and the remaining 30\%in the last period. While only for three fares, the demand data in Table 4 can be representative of actual demand as there is a mix of lower fare and higher fare customers with lower fare requests tending to occur before higher fare requests. The quantity $\mathrm{k}$ is a scaling factor to enable us to vary the demand factor while keeping the coefficient of variation constant. For instance, $\mathrm{k}=1.1$ gives a total expected demand of $5,10 \%$ more than the plane's capacity. Table 5 contains the means and standard deviations for the three period case.

The impact of decision frequency was investigated by increasing the number of periods (from 3 to 6 and 12) by splitting demand in periods in half (from 3 to 6 ) or in quarters (from 3 to 12). Each of the newly created periods is iid, with the same total mean and variance as the parent period they were split from. For example, if the three period scenario with demand factor one of Table 4, was split into six periods, each of the three periods (for each fare class) would be split into two periods with those periods having a mean and variance equal to a half that of the original scenario (maintaining total mean demand and variance across different period scenarios).

In Figure 2, results are presented for the cases where 10, 20, 30, 40 or 50\% of saver customers will defer purchasing if no supersavers are currently available but there is at least a $70 \%$ chance of a supersaver becoming available before the flight departs. Simulations were run for demand factors that vary between 0.75 and 1.35. A demand factor of 0.75 represents a flight with low demand, where perhaps a strategy of not rejecting any requests would be reasonable, with 1.35 representing a flight with stronger demand-where more restrictive control of low-priced fares would be advantageous. The bottom curve in Figure 2 represents the revenue losses as a function of the demand factor if $50 \%$ of customers are willing to delay purchasing a ticket when the probability of a supersaver opening up before departure is at least 70\%. Curves above represent the revenue losses if 40, 30, 20 and 10\% of customers are willing to postpone purchasing. As can be seen in Figure 2, the revenue loss to the airline is more severe when the demand factor is low. For a demand factor of 0.75 and only $10 \%$ of customers being willing to divert, there is more than a $1 \%$ revenue loss. If $50 \%$ are willing to divert, then revenue loss reaches almost 6\%. From the airline industry's point of view, even a percentage point loss has significant impact on profitability. For a demand factor of around 1.15, a revenue loss of more than $1 \%$ is sustained if more than $30 \%$ of customers are willing to defer when there is at least a $70 \%$ chance of a supersaver fare becoming available. So, even in the high demand factor situation, an airline could lose a 
significant portion of revenue when a large fraction of customers is willing to wait for a supersaver class to open.

Table 4 Means and standard deviations of total demand by fare class

\begin{tabular}{lllcc}
\hline & Fare & Mean & Standard deviation & \% demand split by class \\
\hline Full & $\$ 500$ & $17.5 k$ & $5.86 k$ & 35 \\
Saver & $\$ 200$ & $15 k$ & $8.66 k$ & 30 \\
Supersaver & $\$ 100$ & $17.5 k$ & $5.86 k$ & 35 \\
\hline
\end{tabular}

Note: varying $k$ changes the demand factor.

Table 5 Means and standard deviations for three period case with demand factor $k$

\begin{tabular}{|c|c|c|c|c|c|c|}
\hline & \multicolumn{2}{|c|}{ Period 1} & \multicolumn{2}{|c|}{ Period 2} & \multicolumn{2}{|r|}{ Period 3} \\
\hline & Mean & Standard deviation & Mean & Standard deviation & Mean & Standard deviation \\
\hline Full & $1 k$ & $1 k$ & $7.5 k$ & $4.69 k$ & $9 k$ & $3.38 k$ \\
\hline Saver & $5 k$ & $5 k$ & $5 k$ & $5 k$ & $5 k$ & $5 k$ \\
\hline Supersaver & $9 k$ & $3.38 k$ & $7.5 k$ & $4.69 k$ & $1 k$ & $1 k$ \\
\hline Total & $15 k$ & $6.11 k$ & $20 k$ & $8.30 k$ & $15 k$ & $6.11 k$ \\
\hline
\end{tabular}

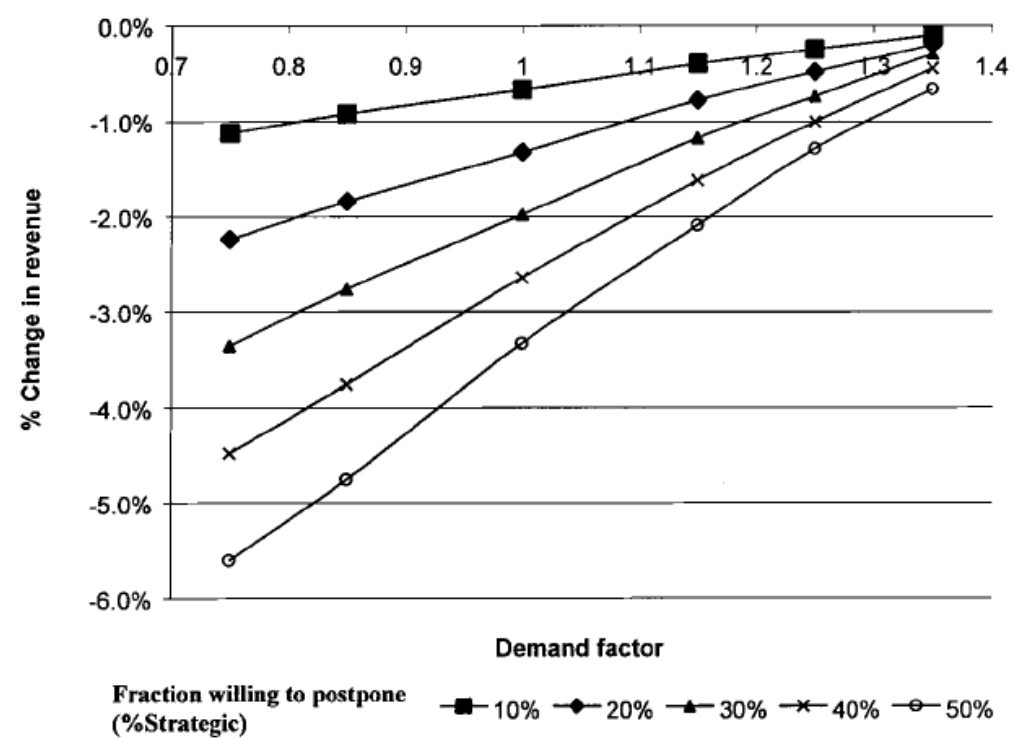

Figure 2 Revenue implications of customers willing to defer purchase if there is at least a $70 \%$ chance of lower fare becoming available. 


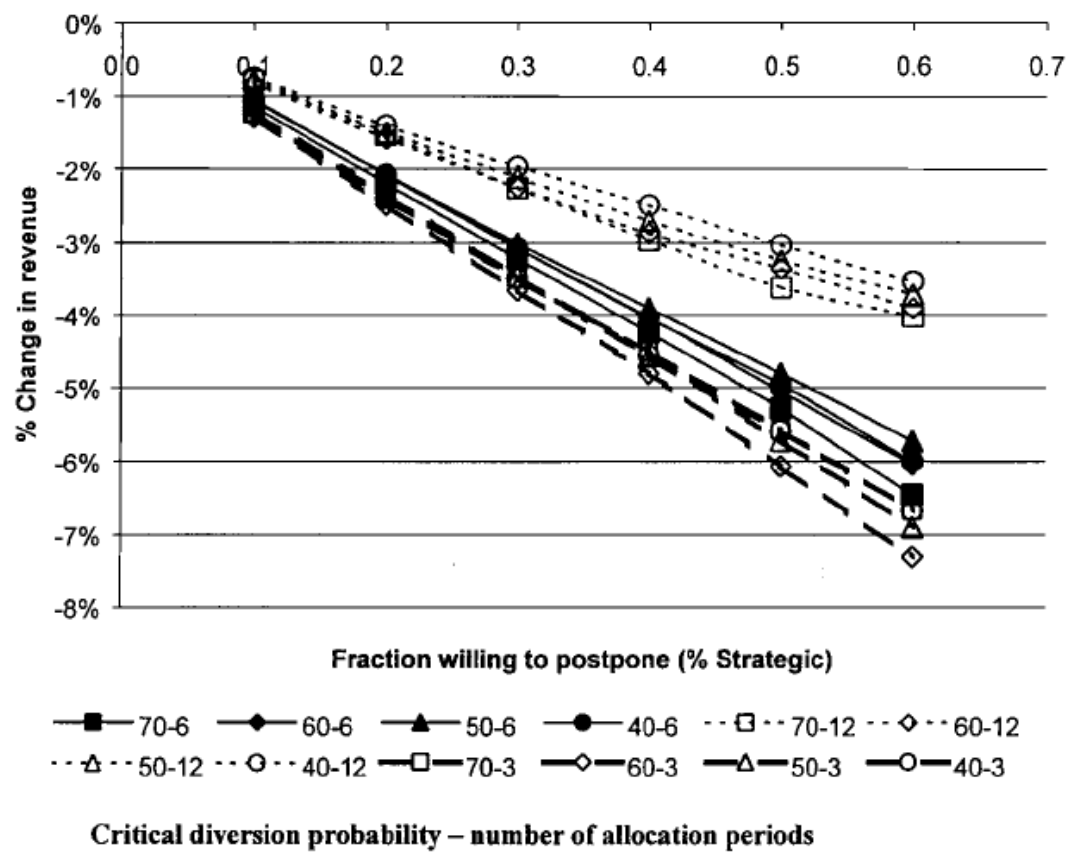

Figure 3 Revenue losses for the case of 3, 6 or 12 reallocation periods and critical probabilities of $70,60,50$ and $40 \%$.

In Figure 3, results are provided for flights where the demand factor is set at 0.85 . The first block of curves (illustrated with dots) contains results for the case where the airline has 12 reallocation periods. The next set of curves (illustrated by full lines) illustrates the impact on revenues if the airline has six reallocation periods, while the bottom block of curves (illustrated by dashes) shows the case of three allocation periods. Each block of curves contains results for four cases: those where the customer might defer purchase if the probability of a supersaver opening up is $0.4,0.5,0.6$ and 0.7 . The bottom curve in Figure 3, for instance, represents the percentage revenue loss as a function of the fraction willing to postpone purchasing a ticket when the probability of a supersaver opening up in the future is at least $40 \%$. As might be expected, Figure 3 illustrates the fact that the more allocation periods the airline has, the more it can adapt to customer behavior and minimize the potential revenue losses.

The price differential between the various fare classes will naturally have an impact on revenue. Results are presented for a high-demand flight (Figure 4) and a low-demand flight (Figure 5). Here we assume that there are six fare reallocation periods and that customers will consider deferring purchase if there is at least a $70 \%$ probability that supersaver fare will reopen. The curves in Figures 4 and 5 represent the cases where a supersaver fare is $25 \%$ (the dashed curve), $50 \%$ (the solid line) and $75 \%$ (the dotted curve) of the saver fare. Both figures indicate interesting results from a pricing standpoint. In Figure 4, the revenue losses from diverting customers can be less with more drastically reduced discount fares-revenue losses when the supersaver fare is $25 \%$ of the saver fare are lower than when it is $50 \%$, 
until over half of customers are willing to wait for the supersaver class to reopen. This can occur since revenue losses are influenced by both the disparity between fares and the probability that a fare will reopen. If this latter is too low, a customer might take the higher fare even if the discounted fare is much lower. In Figure 5, these implications are not as dramatic given the low demand. Under low demand, the probability of reopening is higher (protection levels for full and saver are lower) and diversion occurs more frequently-resulting in similar revenue losses for fare ratios supersaver/saver of0. 25 and 0.5 .

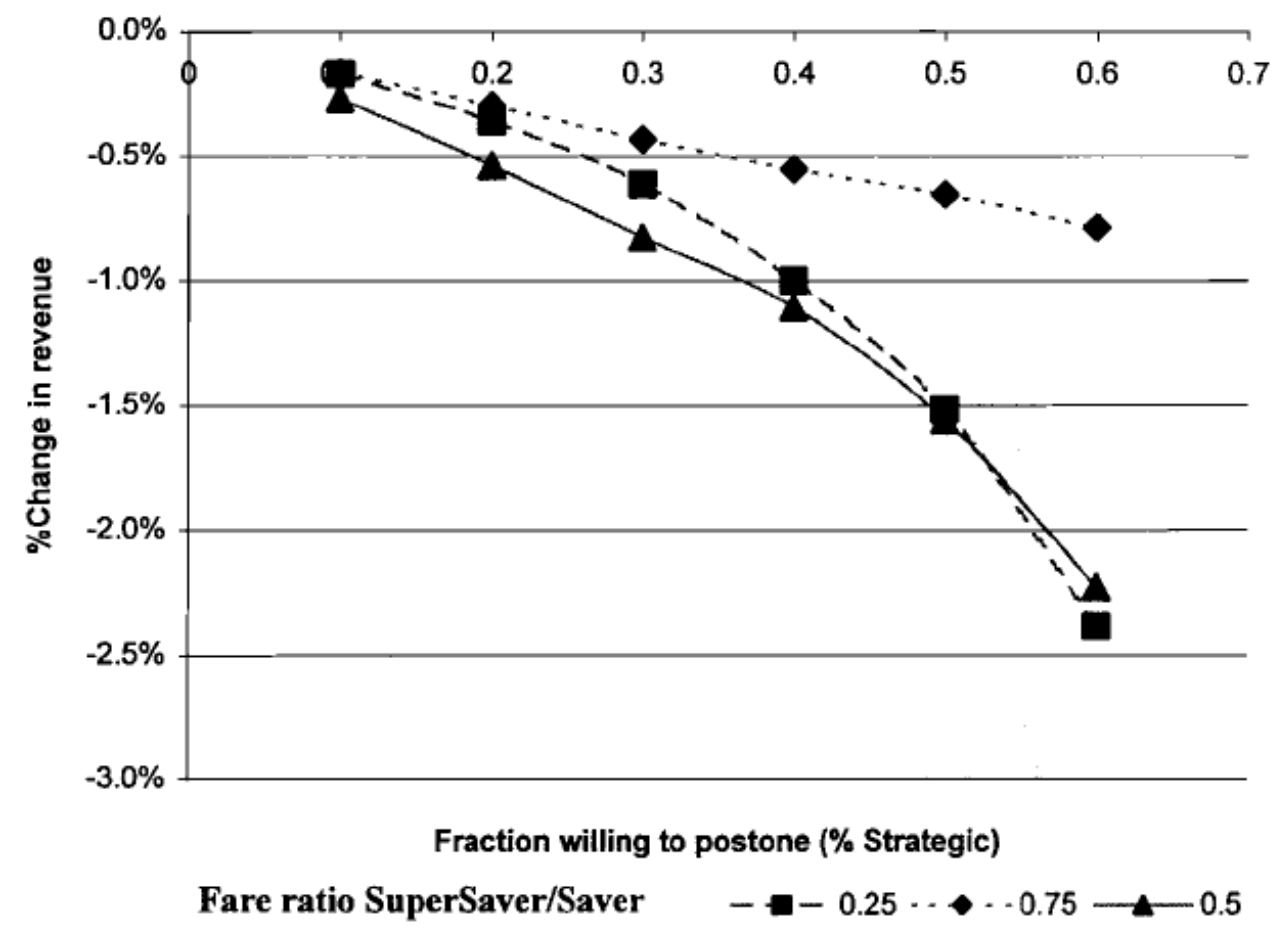

Figure 4 Fare sensitivity, demand factor 1.15. 


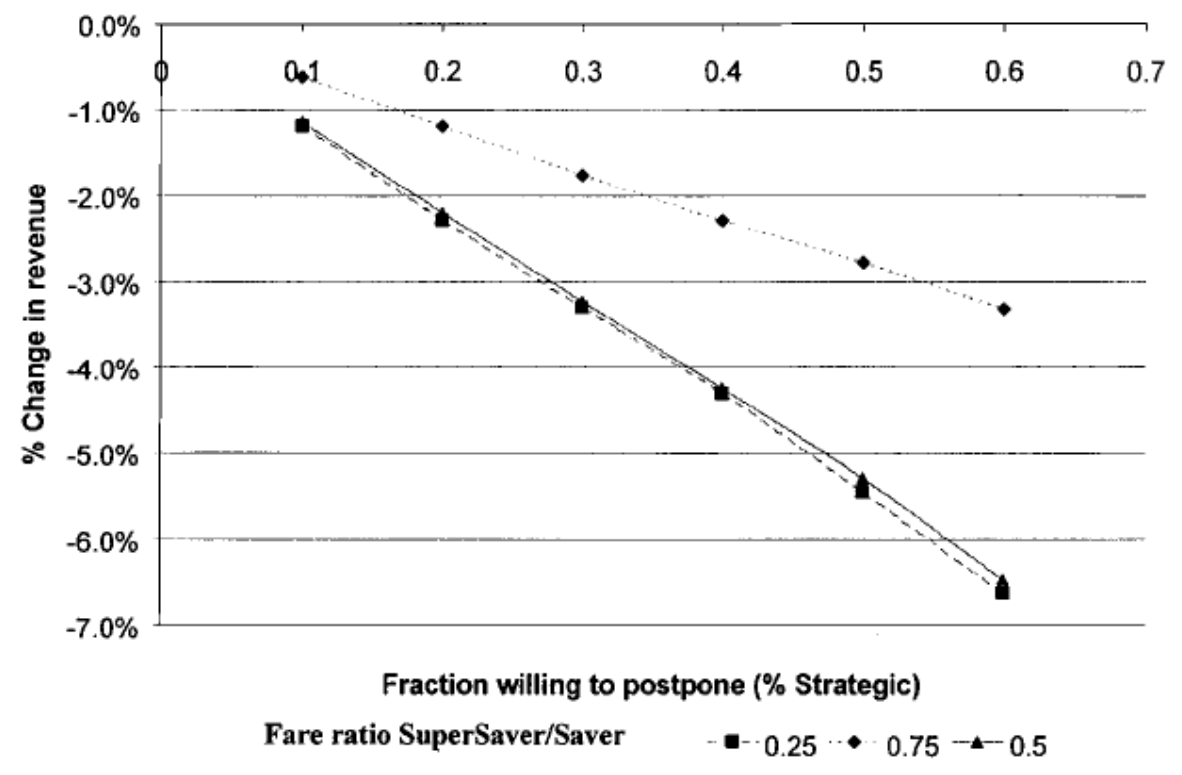

Figure 5 Fare sensitivity, demand factor 0.85 .

\section{Conclusions}

In this paper we have looked at the most important airline yield management pricing systemEMSR. We have demonstrated that it is possible for a consumer or a third party (such as a travel agent or an Internet travel site) to compute the probability that a currently closed fare class will open up at some time in the future. So now the consumer, when confronted with a situation where all of the cheapest fares are gone, may decide to wait before buying a ticket in the hope that a cheaper fare class will reopen. The implications of this strategic behavior on the part of the consumer can have serious revenue implications for the airline. This is particularly true in the case of low demand flights or flights with drastically discounted seats. When the airline sets prices, it should make allowance for strategic behavior on the part of the consumer.

${ }^{1}$ Miller WH (1999). Airlines take to the Internet. Industry Week 248(15): 130-134.

${ }^{2}$ Kalehoff M (2002). Online travel bookings up, despite events of September 11. Jupiter Media Metrix.

${ }^{3}$ McGill Jl and van Ryzin GJ (1999). Revenue management: research overview and prospects. Transport Sci 33: 233-256.

${ }^{4}$ Smith B, Leimkuhler J and Darrow R (1992). Yield management at American Airlines. Interfaces 22(1): 8-31.

${ }^{5}$ Anthes GH (1998). The price had better be right. Computerworld, December 21, pp 65-66.

${ }^{6}$ Harris F and Peacock P (1995). Hold my place, please. Marketing Mngt 4: 34-44. 
${ }^{7}$ Coulter KS (1999). The application of airline yield management to a holiday retail shopping setting. J Prod Brand Mngt 8: 61-72.

${ }^{8}$ Kimes S (1989). Yield management: a tool for capacity-constrained service firms. J Opns Mngt 8: 348363.

${ }^{9}$ Subrahmanyan S (2000). Using quantitative models for setting retail prices. J Prod Brand Mngt 9: 304315.

${ }^{10}$ Stokey N (1979). Intertemporal price discrimination. Q J Econ 93(3): 355-371.

${ }^{11}$ Landsberger M and Meilijson I (1985). Intertemporal price discrimination and sales strategy under incomplete information. Rand J Econ 16: 424-430.

${ }^{12}$ Besanko DA and Winston WL (1990). Optimal price skimming by a monopolist facing rational consumers. Mngt Sci 36: 555-567.

${ }^{13}$ Lazear EP (1986). Retail pricing and clearance sales. Am Econ Rev 76: 14-32.

${ }^{14}$ Elmaghraby W, Gulcu A and Keskinocak P (2001). Analysis of a price markdown mechanism. Proceedings of Third International Workshop on Advanced Issues of E-Commerce and Web-Based Information Systems, San Juan, CA.

${ }^{15}$ Gallego G and van Ryzin GJ (1994). Optimal dynamic pricing of inventories with stochastic demand over finite horizons. Mngt Sci 40: 999-1020.

${ }^{16}$ Littlewood K (1972). Forecasting and control of passenger bookings. AGIFORS Symposium Proceedings 12., Nathanya, Israel.

${ }^{17}$ Belobaba PP (1989). Application of a probabilistic decision model to airline seat inventory control. Opns Res 37: 183-197.

${ }^{18}$ Bhatia A and Parekh S (1973) Optimal allocation of seats by fare. Presentation to AGIFORS Reservations Study Group, Trans World Airlines.

${ }^{19}$ Richter H (1982). The differential revenue method to determine optimal seat allotments by fare type. AGIFORS Symposium Proceedings 22., Lagonissi, Greece.

${ }^{20}$ Titze B and Greisshaber R (1983). Realistic passenger booking behaviors and the simple low-fare/highfare seat allotment model. AGIFORS Symposium Proceedings, p 23., Memphis, TN, USA.

${ }^{21}$ Mayer M (1976). Seat allocation, or a simple model of seat allocation via sophisticated ones. AGIFORS Symposium Proceedings 16., Key Biscayne, FL, USA.

22 Pfeifer P. (1989). The airline discount fare allocation problem. Dec Sci 20: 149-157.

${ }^{23}$ Feldman J (1998). Chasing the rational marketplace. Air Transport World 12: 32-34. 